\title{
An Analytical Model for the Electrolyser Performance Derived from Materials Parameters
}

\author{
Noris Gallandat1,2,3, Krzysztof Romanowicz ${ }^{1,2,3}$, Andreas Züttel1,2,3* \\ ${ }^{1}$ Institute of Chemical Sciences and Engineering (ISIC), Basic Science Faculty (SB), \\ École polytechnique fédérale de Lausanne (EPFL), Lausanne, Switzerland \\ ${ }^{2}$ GRZ Technologies Ltd., Sion, Switzerland \\ ${ }^{3}$ Empa Materials Science \& Technology, Dübendorf, Switzerland \\ Email: *andreas.zuettel@epfl.ch
}

How to cite this paper: Gallandat, N., Romanowicz, K. and Züttel, A. (2017) An Analytical Model for the Electrolyser Performance Derived from Materials Parameters. Journal of Power and Energy Engineering, 5, 34-49.

https://doi.org/10.4236/jpee.2017.510003

Received: September 16, 2017

Accepted: October 27, 2017

Published: October 30, 2017

Copyright $\odot 2017$ by authors and Scientific Research Publishing Inc. This work is licensed under the Creative Commons Attribution International License (CC BY 4.0).

http://creativecommons.org/licenses/by/4.0/

\begin{abstract}
Hydrogen is seen as a key element for the transition from a fossil fuel based economy to a renewable, sustainable economy. Hydrogen can be used either directly as an energy carrier or as a feedstock for the reduction of $\mathrm{CO}_{2}$ to synthetic hydrocarbons. Hydrogen can be produced by electrolysis, decomposing water in oxygen and hydrogen. This paper presents an overview of the three major electrolysis technologies: acidic (PEM), alkaline (AEL) and solid oxide electrolysis (SOEC). An updated list of existing electrolysers and commercial providers is provided. Most interestingly, the specific prices of commercial devices are also given when available. Despite tremendous development of the PEM technology in the past decades, the largest and most efficient electrolysers are still alkaline. Thus, this technology is expected to play a key role in the transition to the hydrogen society. A detailed description of the components in an alkaline electrolyser and an analytical model of the process are provided. The analytical model allows investigating the influence of the different operating parameters on the efficiency. Specifically, the effect of temperature on the electrolyte conductivity-and thus on the efficiency-is analyzed. It is found that in the typical range of operating temperatures for alkaline electrolysers of $65^{\circ} \mathrm{C}-220^{\circ} \mathrm{C}$, the efficiency varies by up to 3.5 percentage points, increasing from $80 \%$ to $83.5 \%$ at $65^{\circ} \mathrm{C}$ and $220^{\circ} \mathrm{C}$, respectively.
\end{abstract}

\section{Keywords}

Electrolysis, Hydrogen Production, Analytical Modeling,

Technology Overview 


\section{Introduction}

The tremendous economic development of the $20^{\text {th }}$ century was largely driven by the availability of abundant, cheap fossil fuels. However, there is now a consensus within the scientific community that $\mathrm{CO}_{2}$ emissions due to fossil fuel combustion are directly correlated with the ongoing climate change [1]. In order to slow down climate change and to prevent the resulting dramatic consequences, there is a need for new, renewable energy sources. The transition from a fossil fuel-to a renewable energy based economy-is already happening in certain countries. In Germany, the contribution of solar electricity to the total electrical consumption increased from less than $0.5 \%$ in 2005 to $7.5 \%$ in 2015 [2]. However, there is one important drawback of renewable energy sources such as wind and solar: these types of energy sources cannot be controlled and are poorly predictable. Thus, new energy storage capacities have to be built to match the energy supply and demand both timely and geographically. Hydrogen has emerged as a possible energy vector to bridge that gap. Hydrogen could be used directly as an energy vector or as a feedstock for the production of synthetic hydrocarbons via carbon dioxide reduction [3] [4]. Both approaches are shown graphically in Figure 1. In the first case (left), hydrogen is produced by using renewable electricity sources through the electrolysis process. The oxygen is released in the atmosphere, and the hydrogen is stored. Upon demand, hydrogen is combusted in order to recover energy, for instance in a fuel cell or in a conventional combustion engine. The synthetic fuel cycle (right) is similar. However, the key difference is that $\mathrm{CO}_{2}$ is included in that cycle. Therefore, synthetic hydrocarbons are produced. The strong advantage of this cycle is the fact that the distribution channels and users' customs do not need to be changed. The challenge lies in the addition of a relatively complex step in the process, i.e. the capture of $\mathrm{CO}_{2}$ from ambient air. In both cases, the advantage is the absence of net $\mathrm{CO}_{2}$ emissions.

Regardless of the approach chosen, the production of hydrogen by electrolysis is a key step of the process. There exist three main types of electrolysers, classified based on the ion transferred: Acidic (PEM) electrolysers, alkaline (AEL) and solid oxide electrolysers (SOEC).

\section{Technology Overview}

Electrolysis is based on the splitting of water by means of an electrical potential (dissociation of the water molecule in an electrical field). Hydrogen is evolved on the cathode (-) and oxygen on the anode $(+)$. Between the electrodes is an electrolyte, which acts as an electrical insulator and ionic conductor. The ions transferred between the electrodes are, either $\mathrm{H}^{+}, \mathrm{OH}^{-}$or $\mathrm{O}_{2}^{-}$and the corresponding electrolysers are called polymer electrolyte membrane, acidic (PEM), alkaline or solid oxide electrolyte. The schematic principle of the three different types of electrolysers is summarized in Figure 2. A membrane separates the evolved gases $\mathrm{H}_{2}$ and $\mathrm{O}_{2}$ between the electrodes. The membrane has to fulfill several 

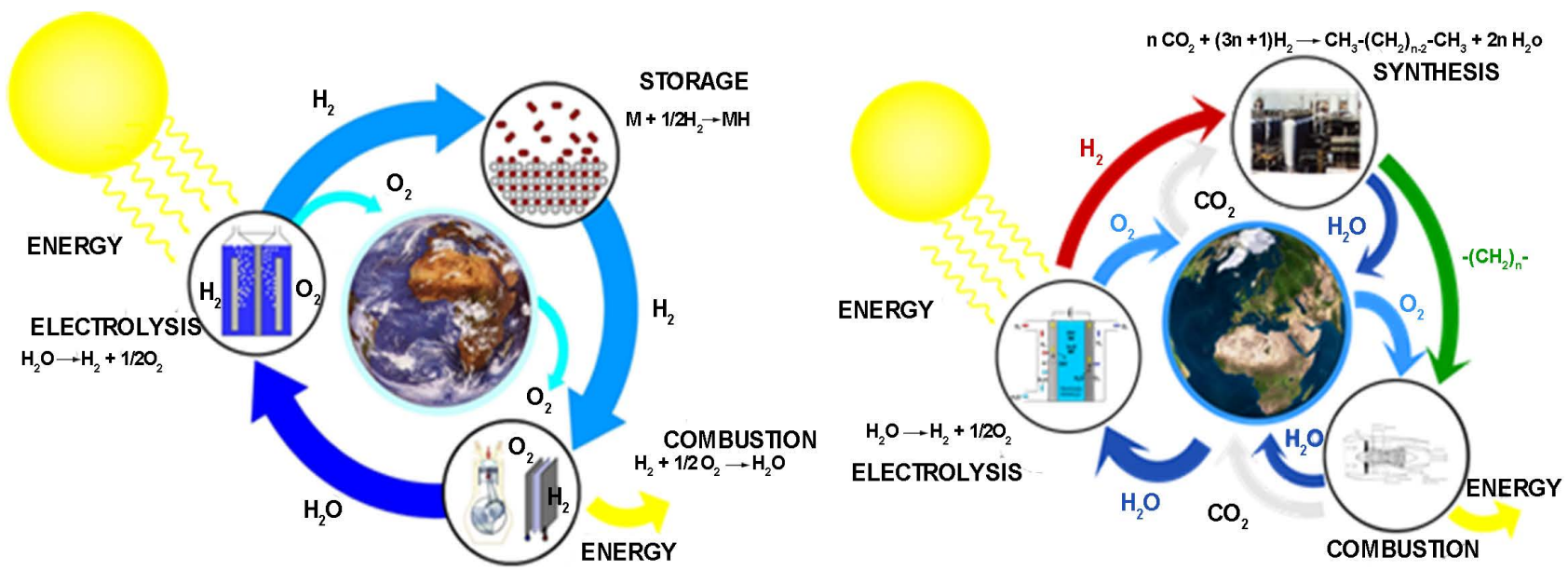

Figure 1. Hydrogen cycle (left) and synthetic fuel cycle (right). Both cycles result in no net $\mathrm{CO}_{2}$ emission.

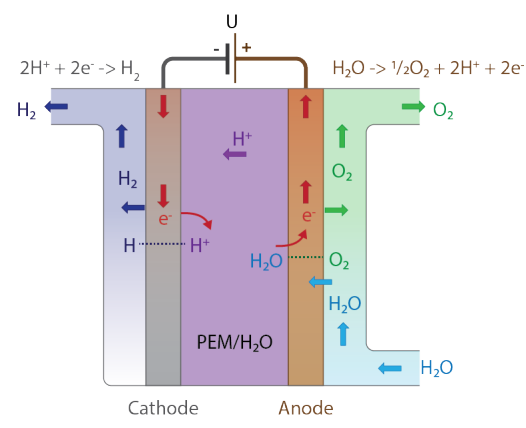

(a)

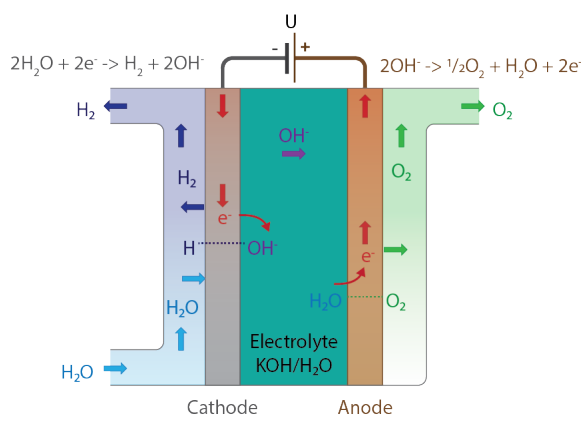

(b)

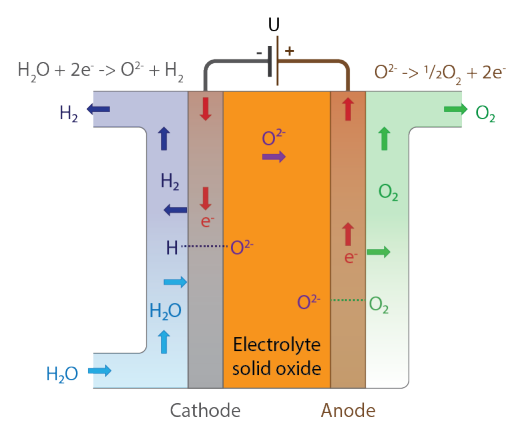

(c)

Figure 2. The three types of electrolysers: (a) Acidic (PEM: Polymer Electrolyte Membrane); (b) Alkaline (AEL); and (c) Solid oxide (SOEC) electrolyser cells.

requirements, e.g. stability under operating conditions, separation of the gases, mechanical separation of the electrodes, ion conduction and mechanical support for pressure differences between the two sides in the cell.

The electrolysers are operated under different conditions such as pressure and temperature. Typically, PEM and AEL devices operate at moderate temperatures $\left(<80^{\circ} \mathrm{C}\right.$ and $<220^{\circ} \mathrm{C}$, respectively) while solid oxide electrolysers operate at elevated temperatures $\left(>600^{\circ} \mathrm{C}\right)$. A summary of the typical key operating parameters for the three types of technologies is shown in Table 1.

In general, PEM electrolysers have a low hydrogen production capacity $(<30$ $\mathrm{Nm}^{3} / \mathrm{h}$ ) and a moderate efficiency while AEL electrolysers have larger production capacity and a higher efficiency. The energy required to produce $1 \mathrm{Nm}^{3}$ of hydrogen is plotted versus the hydrogen production rate for several installations in Figure 3. The lower horizontal axis shows the energy content of the produced hydrogen stream based on the Higher Heating Value (HHV)-i.e. the minimal power required to produce that quantity of energy at a $100 \%$ conversion efficiency. Thereby, the difference is made between the PEM electrolyser efficiency of the full system or the stack only, which is sometimes reported in the documentation. 


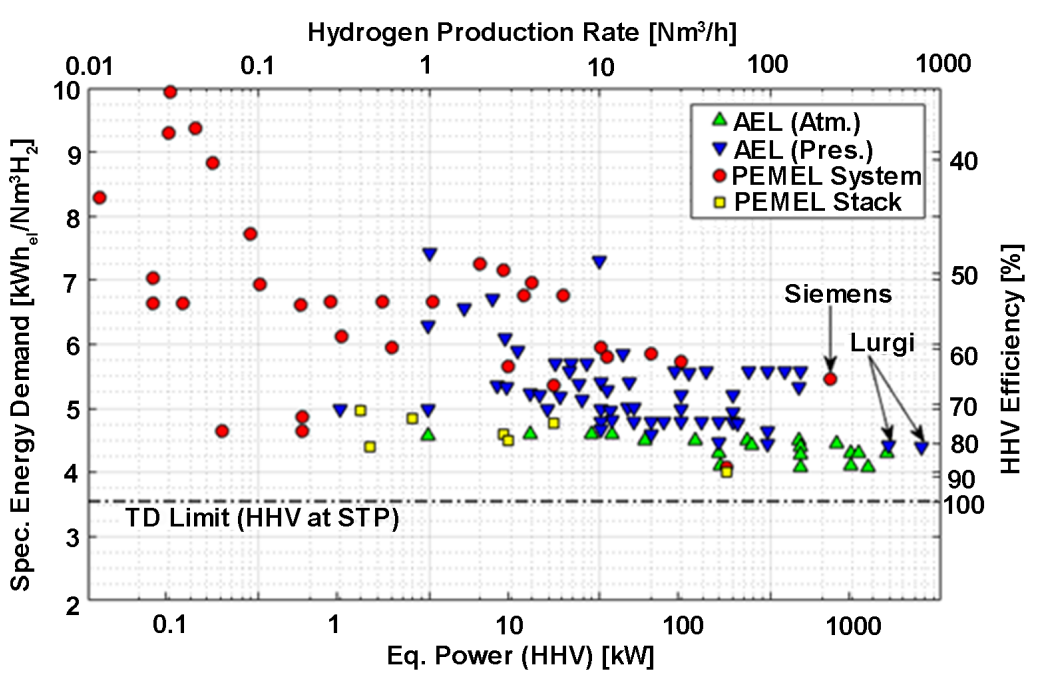

Figure 3. Specific energy consumption of different electrolysers compared to the thermodynamic limit at standard conditions (Adapted and updated from [10]).

Table 1. The three main types of electrolysers with their characteristic parameters and typical operating conditions.

\begin{tabular}{|c|c|c|c|c|c|}
\hline Type & $\begin{array}{c}\text { Operating } \\
\text { Temperature } \\
{\left[{ }^{\circ} \mathrm{C}\right][5]}\end{array}$ & $\begin{array}{l}\text { Operating } \\
\text { Pressure } \\
\text { [Bar] [5] }\end{array}$ & $\begin{array}{c}\text { Cathode } \\
\text { Gas }\end{array}$ & Membrane and Electrolyte & $\begin{array}{c}\text { Anode } \\
\text { Gas }\end{array}$ \\
\hline $\begin{array}{l}\text { Acidic } \\
\text { (PEM) }\end{array}$ & $40-80$ & $<30$ & $\mathrm{H}_{2}$ & $\begin{array}{c}\text { Polymer Electrolyte } \\
\text { Membrane (PEM) } \\
\text { Nafion }{ }^{\circledR} \mathrm{H}^{+}\end{array}$ & $\mathrm{O}_{2}, \mathrm{H}_{2} \mathrm{O}$ \\
\hline $\begin{array}{l}\text { Alkali } \\
\text { (AEL) }\end{array}$ & $65-220$ & $<30$ & $\mathrm{H}_{2}, \mathrm{H}_{2} \mathrm{O}$ & $\begin{array}{l}\mathrm{KOH} \text { Electrolyte } \\
\mathrm{OH}^{-}\end{array}$ & $\mathrm{O}_{2}, \mathrm{H}_{2} \mathrm{O}$ \\
\hline $\begin{array}{l}\text { Solid Oxide } \\
\text { (SOEC) }\end{array}$ & $600-1000$ & $<10^{1}$ & $\mathrm{H}_{2}, \mathrm{H}_{2} \mathrm{O}$ & $\begin{array}{c}\mathrm{ZrO}_{2}, \mathrm{La}_{0.8} \mathrm{Sr}_{0.2} \mathrm{Ga}_{0.8} \mathrm{Mg}_{0.2} \mathrm{O}_{3} \\
\mathrm{O}^{2-}\end{array}$ & $\mathrm{O}_{2}$ \\
\hline
\end{tabular}

Further, it is noticed that hardly any SOEC electrolyser is available commercially at the current stage.

The Lurgi high pressure electrolyzes are still today among the world's most efficient and largest electrolysers, followed by the ambient pressure alkaline electrolysers from NEL (former Norsk Hydro). For a long time, PEM systems were constrained to relatively low production rates (typically less than $30 \mathrm{Nm}^{3} / \mathrm{h}$ hydrogen). Further, large scale alkaline electrolysers currently still exhibit a significantly higher efficiency as compared to PEM systems, even though there are signs that this might change in future. For instance, Siemens is now offering a 1.25 MW PEM electrolyser, the Silyzer 200 [7]. There are only a few suppliers of electrolysers available on the Western market. Very little is known about activities in Asia, though it is certain that companies in China and Japan are working on the development of large scale electrolysers. Hydrogenics delivers alkaline electrolysers $(250 \mathrm{~kW})$ and Proton OnSite delivers PEM electrolysers with a ${ }^{1}$ Pressure effects on brittle membrane make high pressure measurement difficult in SOEC. Experimental measurements at operating pressures up to 10 bar have been reported [6]. 
power up to $100 \mathrm{~kW}$. The specific price of electrolysers per capacity of hydrogen production is represented graphically in Figure 4. This data was collected by the authors based on commercial quotes and from [8]. The data is presented in three different categories differentiating the technology (PEM or Alkaline) and the country of manufacture (US/EU or China). It is interesting to notice that the price per capacity decreases exponentially with the size of the electrolysers and approximately at the same rate, regardless of the technology or the country of manufacturing. Further, it is striking to see that suppliers from China offer products that are typically an order of magnitude cheaper than equivalent products from Western manufacturers. For instance, a PEM electrolyser from China with a production capacity of $180 \mathrm{Nl} / \mathrm{hr}$ was offered at a price of USD 5400 . However, there is no certainty about the reliability and quality of these low-cost solutions and this is certainly an aspect that needs to be further investigated. A list of current electrolyser suppliers developed by Bertuccioli et al. was updated and is reproduced in Table 2 [9].

\section{Components of an Alkaline Electrolyser}

Alkaline electrolyte electrolysers represent a very mature technology that is the current standard for large-scale electrolysis [11]. The key components of an alkaline electrolyser are the electrolyte, electrodes, the separator and a container. The characteristics of each of these components are presented in this section.

\subsection{Electrolyte}

The electrolyte in these systems is a liquid based on a highly caustic $\mathrm{KOH}$ solution. The ionic charge carrier is the hydroxyl ion, $\mathrm{OH}^{-}$, and a membrane porous to hydroxyl ions but impermeable to $\mathrm{H}_{2}$ and $\mathrm{O}_{2}$, thus providing gas separation. In the zero-gap cell design, the electrode materials are pressed on either side of the diaphragm so that the hydrogen and oxygen gases are forced to leave the electrodes at the rear, as shown in Figure 5. Most manufacturers have adopted this design.

The hydrogen molecules accumulate on the surface of the electrode until a bubble forms, breaks away, and rises to the surface of the electrolyte. At the oxygen electrode, a similar process occurs in which hydroxyl ions are discharged by giving up their electrons to the electrode and reacting to form water and oxygen. The oxygen molecules accumulate into gas bubbles and rise to the surface. Both of these electrode reactions require some intermediate catalytic reaction with a metal surface. It is believed that the hydrogen ions discharge on the metal surface to form an adsorbed layer of hydrogen atoms, which then recombine on the surface to form hydrogen molecules. The ease with which the electrode reactions occur is profoundly affected by both the physical and chemical natures of the surfaces of the electrodes. Maximum conductivity occurs in $\mathrm{KOH}$ solutions at a concentration $20 \%-30 \%$, and this is the concentration usually selected [12]. There is one notable exception to the use of alkaline electrolytes, which is the use of a solid polymeric ion-exchange material that also has good ionic conductivity. 
Table 2. List of electrolyser suppliers (not exhaustive) and key performance metrics of the largest device available collected from data sheets. Updated and adapted from [10].

\begin{tabular}{|c|c|c|c|c|c|c|c|c|}
\hline Company & Country & Type & Model & $\begin{array}{l}\text { Capacity } \\
{\left[\mathrm{Nm}^{3} / \mathrm{hr}\right]}\end{array}$ & $\begin{array}{l}\text { H2 Output } \\
\text { Pressure } \\
\text { [barg] }\end{array}$ & $\begin{array}{c}\text { H2 Purity } \\
\text { [\%] }\end{array}$ & $\begin{array}{c}\text { Electrical } \\
\text { Consumption } \\
{\left[\mathrm{kWh} / \mathrm{kgH}_{2}\right]}\end{array}$ & $\begin{array}{c}\text { HHV } \\
\text { Efficiency } \\
{[\%]}\end{array}$ \\
\hline Acta & Italy & AEM & EL1000 & 1 & 29 & 99.94 & 53.2 & $74.0 \%$ \\
\hline AREVA H2 Gen & France & PEM & E120 & 120 & 35 & 99.999 & 53.8 & $73.2 \%$ \\
\hline Erredue & Italy & Alkaline & G256 & 170 & 30 & 99.5 & 59.5 & $66.2 \%$ \\
\hline H-TEC SYSTEMS & Germany & PEM & EL30/144 & 3.6 & 29 & N/A & 55.4 & $71.1 \%$ \\
\hline Hydrogenics & $\begin{array}{l}\text { Belgium, } \\
\text { Canada }\end{array}$ & $\begin{array}{c}\text { Alkaline } \\
\text { (PEM in dev.) }\end{array}$ & HyStat60 & 60 & 10 & 99.998 & 58.2 & $67.7 \%$ \\
\hline Idroenergy & Italy & Alkaline & Model120 & 80 & 5 & 99.5 & 62.7 & $62.8 \%$ \\
\hline ITM Power & UK & $\begin{array}{c}\text { PEM } \\
\text { (AEM in dev.) }\end{array}$ & HGas1000 & $\begin{array}{c}132 \\
\text { (Peak: 462) }\end{array}$ & 19 (Opt. 79) & 99.999 & N/A & N/A \\
\hline NEL Hydrogen & Norway & Alkaline & A485 & 485 & Atm. & $>99.9$ & $42.5-49.3$ & $79.9 \%-92.6 \%$ \\
\hline McPhy & France & Alkaline & McLyzer & 60 & 12 & $>99.5$ & 57.8 & $68.1 \%$ \\
\hline Proton OnSite & USA & PEM & Hogen C30 & 30 & 30 & 99.9998 & 65.0 & $60.6 \%$ \\
\hline Siemens & Germany & PEM & SILYZER200 & 225 & 34 & 99.5 & N/A & $65 \%-70 \%$ \\
\hline Teledyne Energy System & USA & Alkaline & EL-N & 500 & 9 & 99.999 & N/A & N/A \\
\hline $\begin{array}{c}\text { Wasserelektrolyse } \\
\text { Hydrotechnik }\end{array}$ & Germany & Alkaline & EV150 & 220 & Atm. & 99.9 & 59.1 & $66.6 \%$ \\
\hline
\end{tabular}

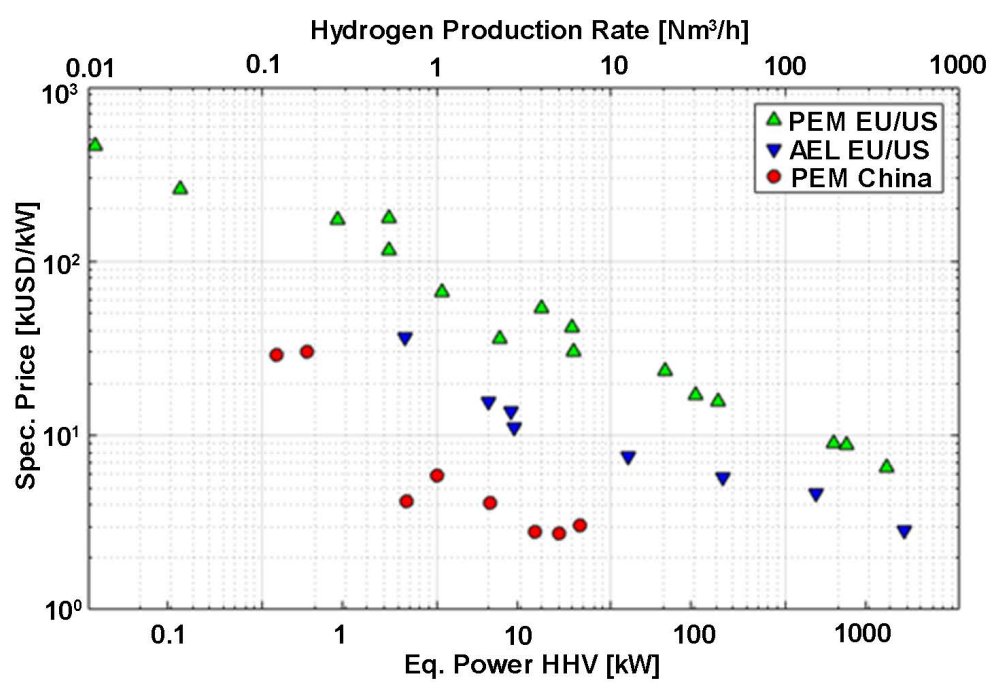

Figure 4. Specific price of electrolysers per production capacity.

Ion-exchange resins having mobile negative ions (in other words, alkaline ion-exchange resins) are notoriously sensitive to chemical degradation at elevated temperatures, and this restricts the choice of ion-exchange electrolytes to acidic systems. The most successful work with ion-exchange electrolytes has been carried out using a polymerized fluorinated polystyrene sulphonic acid [13] [14]. 


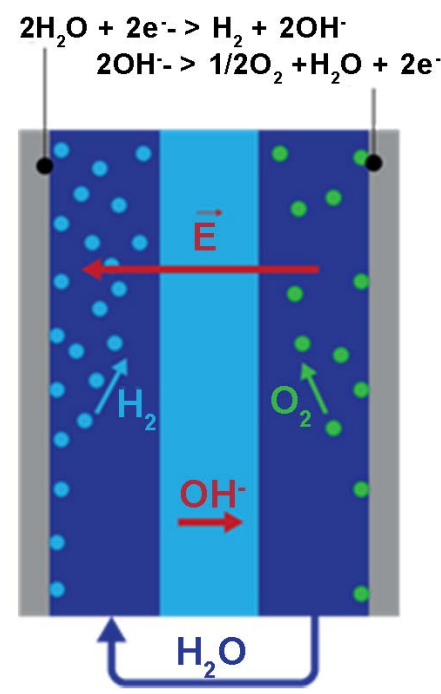

(a)

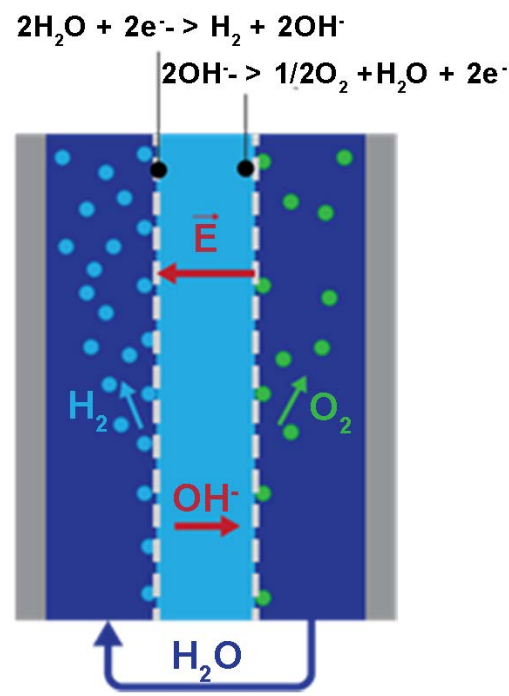

(b)

Figure 5. Schematic representation of (a) alkaline electrolyser and (b) zero-gap alkaline electrolyser.

\subsection{Electrodes}

Electrolysers electrodes must be electronic conductors, have a suitable catalytic surface for the discharge of hydrogen or hydroxyl ions and provide a large area interface between the catalyst and the electrolyte [15]. Further, they must provide adequate sites for nucleation of gas bubbles and favorable properties for the detachment of gas bubbles so that they may separate from the electrolyte at the operating voltage of the cell. The form of the electrodes varies considerably from one cell design to another. The anode and cathode materials in these systems are typically made of nickel-plated steel and steel, respectively [16] [17]. Large surface areas are obtained by the use of sintered structures, finned bodies, screens, perforated plates and flat plates with electrochemically roughened surfaces. In the alkaline cells, nickel is the most commonly used catalytic surface. Rather than making electrodes out of solid nickel, nickel-plated mild steel is often used. The application of precious-metal catalysts, such as platinum, assists the electrode processes considerably and allows them to proceed more rapidly than on nickel [18]. However, the extra cost of the precious metal is usually not considered justified. In the case of the polymeric acid electrolyte, electrodes must be made of materials chemically more resistant than nickel or steel. Tantalum and gold have been used, while the precious metals themselves, platinum, rhodium, iridium, etc. are usually considered necessary as catalysts. When platinum is used, a large surface area can be obtained by the use of so-called platinum black, a finely divided powder of platinum metal particles.

\subsection{Separator}

A separator is required between the two electrodes for two reasons. First, it prevents the electrodes from creating a short circuit. Second, it prevents hydrogen and oxygen from mixing within the cell. An effective separator must consist of a 
porous diaphragm or matrix permeable to the electrolyte solution affording an ionic conducting path from one side of the cell to the other. These pores must remain full of liquid so that gas cannot penetrate. Additionally, the separator material must not be corroded by the electrolyte in the presence of hydrogen or oxygen gas and must remain structurally stable for the entire operating life of the cell so that the pores do not collapse. In order to keep the ionic resistance of the cell as low as possible, the separator is usually made in the form of a thin sheet, the thickness of which is determined by mechanical strength and gas crossover limitations. In the case of alkaline cells, asbestos has commonly been used for the separator material. However, this material has now been removed from commercial devices because of health hazards. Some experimental materials such as potassium titanate have been used in other alkaline cells [19]. Currently, most commercial alkaline electrolysers are using a separator of the type Zirfon UTP 500 , which is a hydrophilic polyphenylene sulphide fabric coated with a mixture of a polymer and zirconium oxide [20]. More recently, there was an increased interest in composite membranes based on polysulfone and mineral fillers. These membranes were measured to have superior performance than commercially available products with the additional advantage of allowing higher operating temperatures [21].

\subsection{Container}

Finally, a container is required to hold the electrolyte. In some cells, a nickel-plated steel tank with a lid is used. In others, solid metal sheets are interposed between the electrodes, which are then stacked together with peripheral gaskets used to seal the outer edges. In this way, no separate container is required and the current is passed from one electrode to the next through the metal separator plate.

\subsection{System}

In addition to the basic components of the electrolyser cell itself, an electrolyser system requires further components. These include power electronics to convert AC power to the DC current required by the cell, an electrical bus bar equipment to distribute the DC power to the various electrodes in an assembly of electrolyser cells, gas-exit pipe work to duct the hydrogen and oxygen away from the cell, separation systems to separate the gases from the electrolyte, which may be entrained with the gas or deliberately circulated out of the cell with the gas, cooling systems to remove waste heat from the cell itself and, finally, drying systems to dry the hydrogen and oxygen after they have been generated. The typical operating temperatures and pressures of these electrolysers are $65^{\circ} \mathrm{C}-220^{\circ} \mathrm{C}$ and 1 - 30 bar, respectively [5]. The layout for a typical alkaline electrolysis plant is shown in Figure 6.

In practice, filter-press-type cells are usually constructed with separate electrodes in each cell that are electrically connected through a solid metal separator plate that serves to keep the hydrogen cavity of one cell separate from the oxygen 


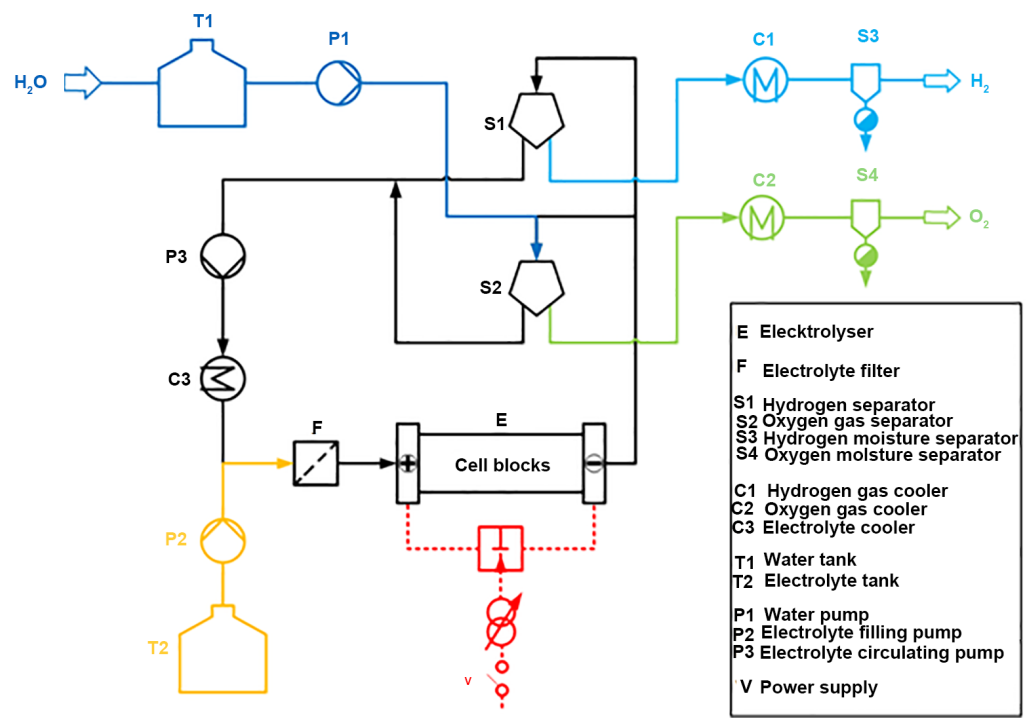

Figure 6. Layout for an alkaline electrolysis plant.

cavity of the next one. Because the cells of the filter-press-type electrolyser can be relatively thin, a large gas output can be achieved from a relatively small piece of equipment. It is usually necessary to cool the cells by circulating the electrolyte through them, and the electrolyte exiting from the cell carries with it the gas produced. In many designs, separation of the gas from the electrolyte is accomplished in a separating drum mounted on top of the electrolyser. The electrolyte, free of gas, is re-circulated through the cells. The major advantages of filter-press-type electrolysers are that they take up less floor space than the tank-type design; they are more amenable to operation at high pressures and high temperatures. On the downside, filter-press-type electrolysers require a much closer tolerance in construction because of sealing problems and are more difficult to maintain because if one cell fails, the entire battery has to be dismantled and production of hydrogen is lost. Filter-press electrolysers usually present higher capital costs per unit area than tank-type cells, and, to compensate for this, they are operated at higher current densities.

The bipolar design has been universally accepted as offering the most potential for incorporation of advanced technology. This is in part due to the intangible attractions of the highly-engineered bipolar cells, and to the recent development of new bipolar concepts for application in cost-insensitive aerospace applications. Also, cost and performance projections for bipolar electrolyser equipment have been erroneously compared with data for early unipolar plants, which are not representative of the potential of the unipolar approach. There is, in fact, a clear distinction between unipolar electrolyser technology and the older designs on which most published comparisons with bipolar equipment have been based.

Typically, there are tradeoffs related to an increase in current density. At a higher current density, the investment costs are reduced but the electricity consumption and thus the operational cost are increased. In order to further en- 
hance the performance of alkaline electrolysers, Ulleberg suggested three axis of research: 1) develop new cell configuration to reduce the surface-specific cell resistance; 2 ) increase the process temperature to increase the electrolyte conductivity and thus reduce the cell resistance; and 3) research new electrocatalysts in order to decrease the anodic and cathodic overpotentials [12].

\section{Analytical Modeling of AEL Electrolysers}

The water decomposition reaction occurring in electrolysis is shown in Equation (1). The standard enthalpy of reaction and change in entropy are calculated in Equation (2) and Equation (3), respectively. Thereby, water is considered as a liquid.

$$
\begin{gathered}
\mathrm{H}_{2} \mathrm{O} \rightarrow \mathrm{H}_{2}+\frac{1}{2} \mathrm{O}_{2} \\
\Delta H_{\mathrm{R}}^{0}=H_{\mathrm{H}_{2}}^{0}+\frac{1}{2} H_{\mathrm{O}_{2}}^{0}-H_{\mathrm{H}_{2} \mathrm{O}}^{0}=286.03 \mathrm{~kJ} / \mathrm{mol} \\
\Delta S_{R}^{0}=S_{\mathrm{H}_{2}}^{0}+\frac{1}{2} S_{\mathrm{O}_{2}}^{0}-S_{\mathrm{H}_{2} \mathrm{O}}^{0}=0.163 \mathrm{~kJ} / \mathrm{mol} \cdot \mathrm{K}
\end{gathered}
$$

The minimal work that has to be applied for the reaction to happen is calculated using Equation (4). The left hand side corresponds to the minimal amount of energy that has to be provided in the form of work, e.g. as electricity. The last term on the right hand side of the equation represents the maximal fraction of the reaction enthalpy that can be provided in the form of heat.

$$
\Delta G_{R}^{0}=\Delta H_{R}^{0}-T \Delta S_{R}^{0}
$$

Using the values of $\Delta H_{R}^{0}$ and $\Delta G_{R}^{0}$, two important potentials can be calculated: the reversible potential $V_{r e v}$ and the thermoneutral potential $V_{t h}$, as shown in Equation (5) and Equation (6), respectively. Thereby, $n$ is the number of electrons transferred $(n=2)$, and $F$ is Faraday's constant $(F=96487 \mathrm{C} / \mathrm{mol})$.

$$
\begin{gathered}
V_{\text {rev }}=\frac{\Delta G^{0}}{n F} \\
V_{t h}=\frac{\Delta H^{0}}{n F}
\end{gathered}
$$

$V_{\text {rev }}$ corresponds to the minimum cell voltage required for a reversible process when heat is provided by the surroundings. The thermoneutral potential $V_{t h}$ is the voltage required if the cell operates adiabatically, i.e. no heat is lost or added to the cell during the process. At room temperature, $V_{\text {rev }}=1.28 \mathrm{~V}$ and $V_{t h}=1.48$ $\mathrm{V}$, respectively. The thermoneutral potential is higher because it includes the heat linked to the change in entropy occurring in the reaction. The efficiency of the electrolysis process is defined as the thermoneutral potential divided by the applied voltage, as shown in Equation (7).

$$
\eta_{e l}=\frac{V_{t h}}{V_{a p p}}
$$

It is interesting to notice that, using this definition, an efficiency higher than 
$100 \%$ is theoretically achievable. However, this can only be the case when heat is transferred from the surroundings to the fuel cell. The thermodynamics of the water dissociation reaction and the corresponding voltages are represented graphically as a function of the temperature in Figure 7. The enthalpy, free Gibbs energy and the entropy of the reaction are shown on the vertical left axis. The corresponding voltage contributions are shown on the vertical right axis. It is interesting to notice that the amount of energy that can be supplied in the form of heat increases with increasing temperature. In this case, the electrolysis process is endothermic [22]. However, the thermoneutral potential remains relatively constant across a wide range of temperatures, except for a discrete change at the boiling point of water.

In practice, the applied voltage required to dissociate water into hydrogen and oxygen does not only depend on the above thermodynamic parameters, but additional voltage drops in the system have to be considered to account for the different losses. The actual required voltage can be calculated in Equation (8).

$$
V_{\text {app }}=V_{t h}+\frac{i}{C} \frac{y}{P}+\left(R_{A}+R_{C}\right) i
$$

Thereby, $i$ is the current density $\left[\mathrm{A} / \mathrm{m}^{2}\right], C$ is the electrolyte conductivity $[\mathrm{S} / \mathrm{m}], y$ is the membrane thickness $[\mathrm{m}], P$ the porosity of the membrane, $R_{A}$ and $R_{C}$ the resistance of the anode and the cathode [Ohm-cm], respectively. The approach of determining the required applied voltage by considering the individual resistances is not new [22]. The novelty of this work, however, is the consideration of the temperature dependence of the electrolyte's conductivity $C$. A current-voltage curve for a typical alkaline electrolyser is shown in Figure 8. Thereby, the losses due to electrical conduction are further decomposed in ohmic losses through the electrodes and losses due to conduction in the electrolyte. In practice and for zero-gap alkaline electrolysers, the ohmic losses are much lower than the other contributions and are therefore neglected in Equation (8). An interesting

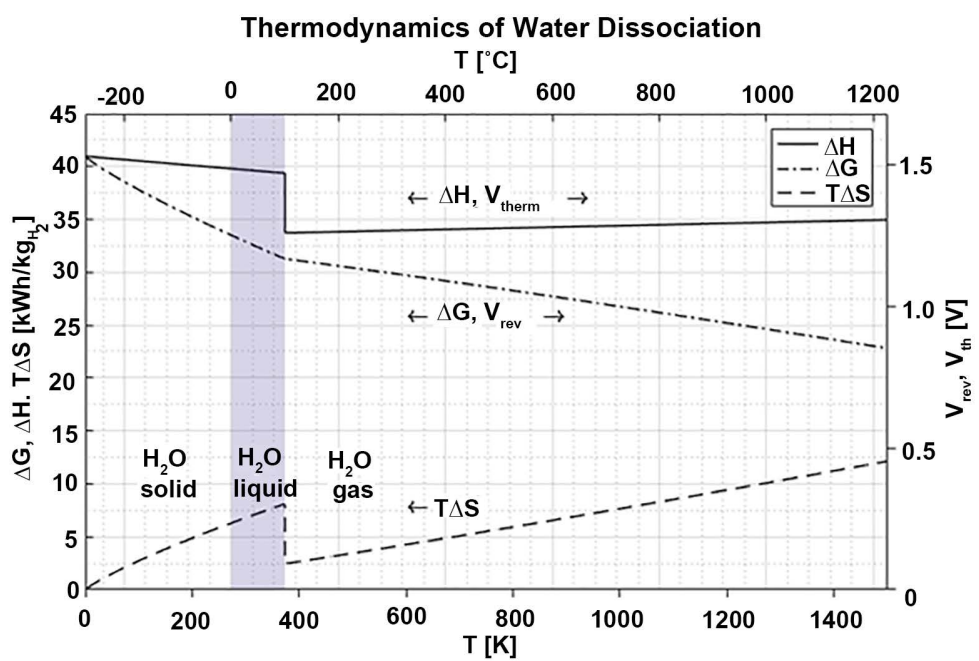

Figure 7. Thermodynamics and corresponding voltages of the water dissociation reaction as a function of the temperature. 


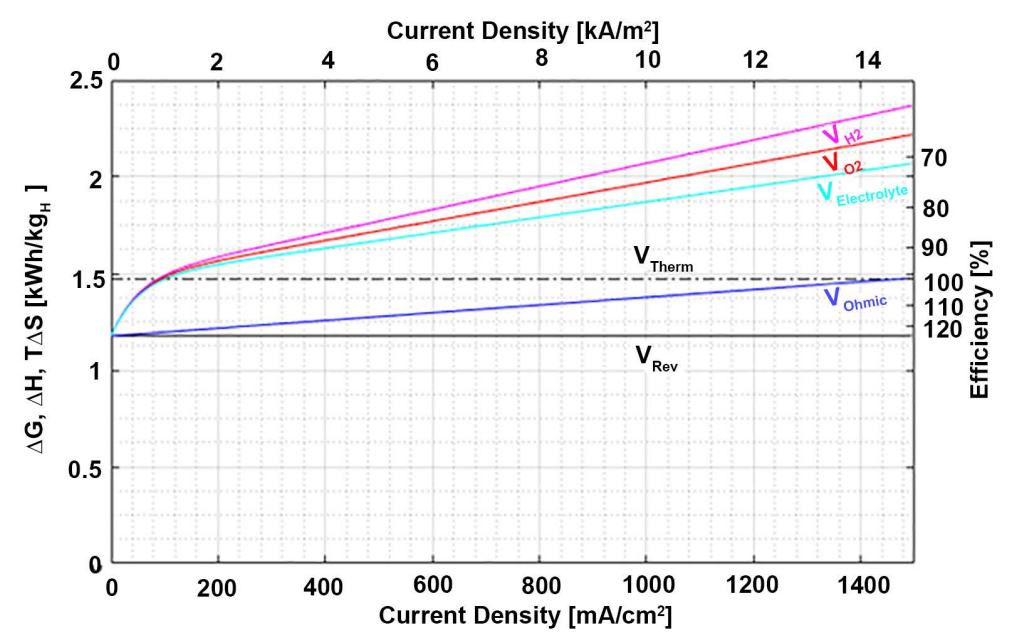

Figure 8. Different contributions of the applied voltage as a function of the current density.

aspect of the graph shown in Figure 8 is the nonlinear behavior of the voltage as the current tends to zero. This is due to the fact that a fraction of the energy required for the water splitting reaction can be provided in the form of heat. At zero current, no heat is generated. As the current density increases, heat is generated proportionally to the square of the current. Thus, the voltage follows this non-linear trend to the point at which the thermo-neutral potential is reached. Past this point, the linear relationship between current density and applied voltage shown in Equation (8) is valid again.

An important parameter that is seldom considered but has an important impact on the efficiency of the electrolyser cell is the temperature dependence of the electrolyte conductivity [23] [24] [25]. The conductivities of typical electrolytes used in PEM, AEL and SOEC electrolysers are plotted as a function of the temperature in Figure 9. These curves can be described by Equation (9), and the corresponding parameters are summarized in Table 3.

$$
\log (C)=a+\frac{b}{T}
$$

Finally, the purity of the hydrogen and oxygen produced can be calculated following Equation (10) and Equation (11), respectively. Thereby, $p_{\mathrm{O}_{2}}$ and $p_{\mathrm{H}_{2}}$ are the permeability to $\mathrm{O}_{2}$ and $\mathrm{H}_{2}$, respectively, $p$ is the operating pressure, $y$ is the thickness of the membrane, $d$ is the diameter of the cell and $V$ is the volumetric flow rate of hydrogen.

$$
\begin{aligned}
& x_{\mathrm{H}_{2}}=1-\frac{p_{\mathrm{O}_{2}} p}{y} \frac{\pi d^{2}}{4} \frac{1}{\dot{V}} \\
& x_{\mathrm{O}_{2}}=1-\frac{p_{\mathrm{H}_{2}} p}{y} \frac{\pi d^{2}}{4} \frac{1}{\dot{V}}
\end{aligned}
$$

Equations (2) to (11) are implemented for a typical alkaline electrolyser. The values of the parameters used are summarized in Table 4. 


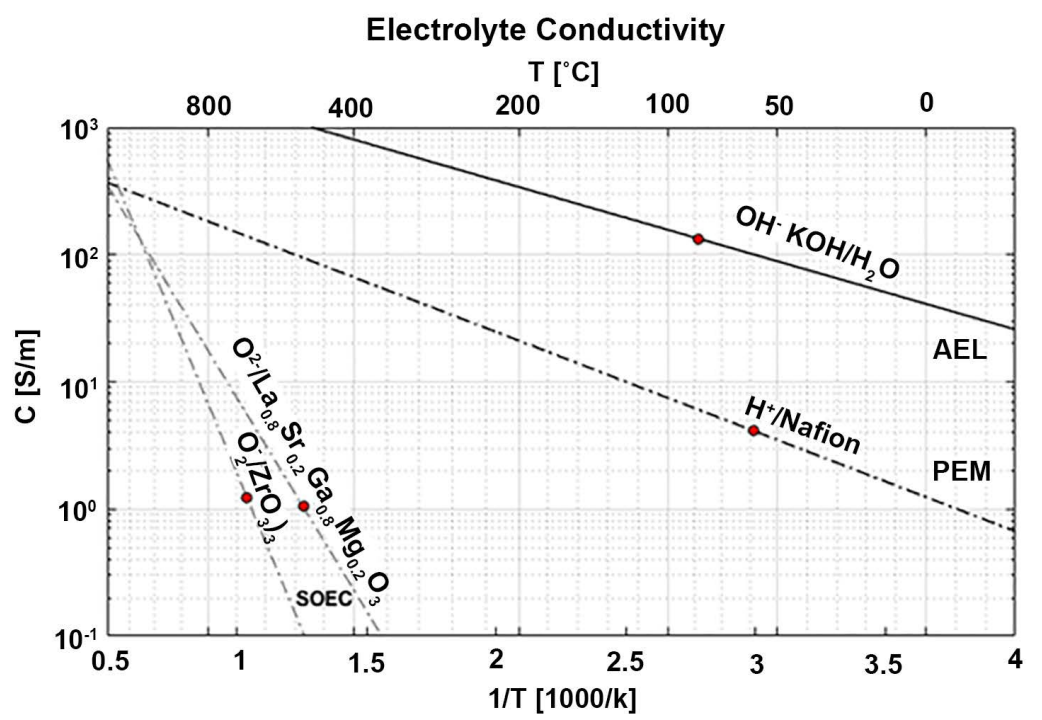

Figure 9. Electrolyte conductivity for different types of electrolysers as a function of the temperature. The red dots indicate typical operating points of the different electrolysers.

Table 3. Parameters for the temperature dependent conductivity of different electrolytes.

\begin{tabular}{ccc}
\hline Type & $\mathrm{a}[-]$ & $\mathrm{b}[\mathrm{K}]$ \\
\hline Acidic (PEM) & 3.005 & -795.2 \\
Alkali (AEL) & 3.789 & -594.3 \\
Solid Oxide (SOEC, $\mathrm{ZrO} 2)$ & 5.500 & -5000.0 \\
Solid Oxide (SOEC, $\left.\mathrm{La}_{0.8} \mathrm{Sr}_{0 .} 2 \mathrm{Ga}_{0.8} \mathrm{Mg}_{0.2} \mathrm{O}_{3}\right)$ & 4.420 & -3400.0 \\
\hline
\end{tabular}

A trend of interest is the behavior of the efficiency as a function of the temperature. As seen from Figure 7, the themoneutral potential remains roughly constant across a wide range of temperatures. However, as the electrolyte conductivity varies with temperature, so does the corresponding voltage drop. This behavior is shown in Figure 10. It is noted that an increase of the operating temperature form $65^{\circ} \mathrm{C}$ to $225^{\circ} \mathrm{C}$ results in an efficiency gain of 3.5 percentage points from $80 \%$ to $83.5 \%$ due to the higher conductivity of the electrolyte at elevated temperatures.

\section{Conclusion}

An overview of the electrolysis technologies was provided. Currently, there exist three major types of electrolysers: PEM, AEL and SOEC. Current providers of commercial electrolysers are reported and existing devices are plotted on a capacity-efficiency diagram. Typically, PEM devices deliver low volume of hydrogen at a moderate efficiency while AEL electrolysers produce larger amounts $\left(>1 \mathrm{Nm}^{3} / \mathrm{hr}\right.$ ) of hydrogen at a higher efficiency. Further, the data for the prices of electrolysers is represented graphically. It is seen that the specific price per capacity decreases exponentially with increasing capacity. Further, it is noted 
Table 4. Parameters used to model the performance of an alkaline electrolyser.

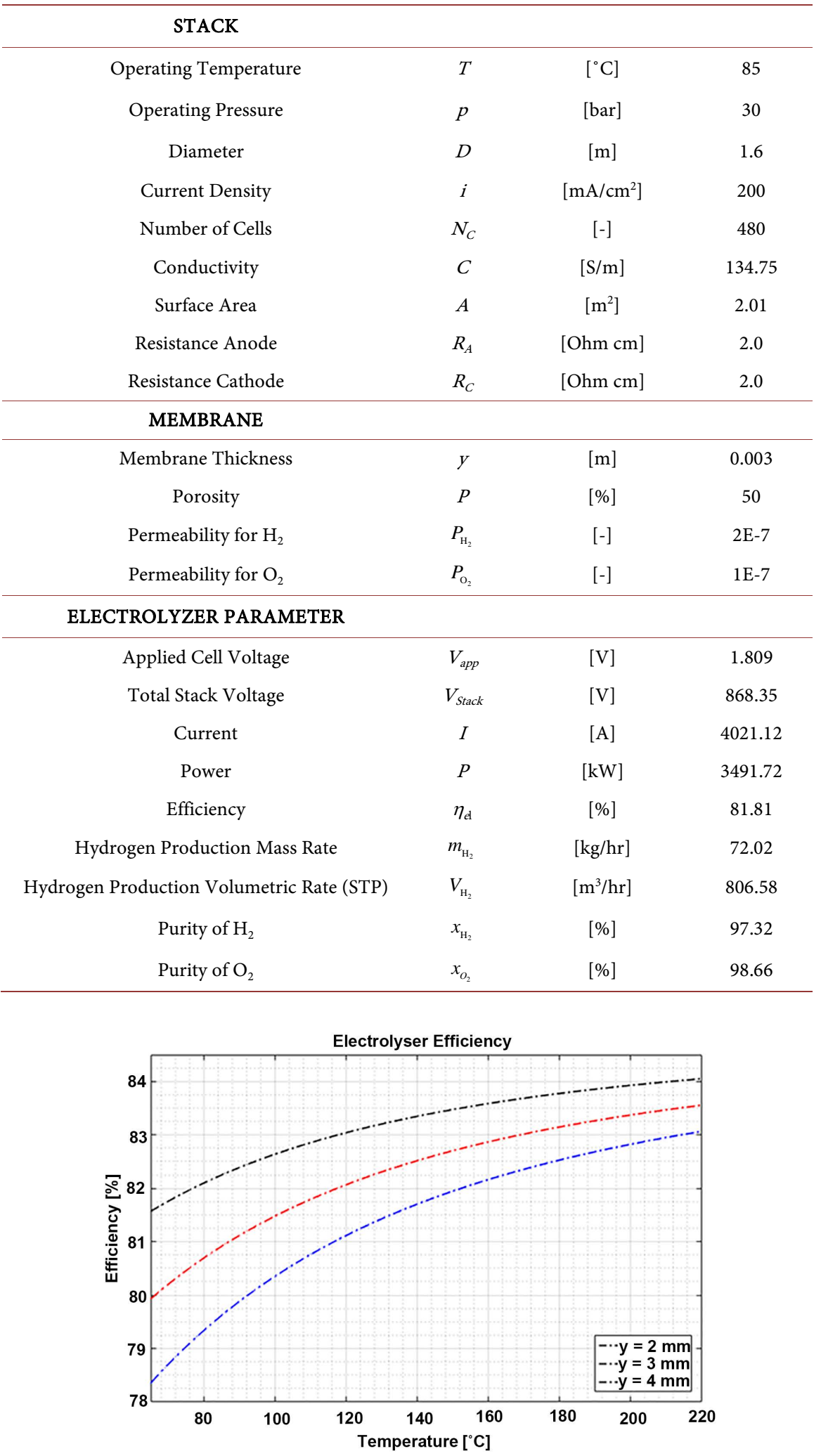

Figure 10. Electrolyser efficiency as a function of the operating temperature. The parameters of the electrolyser are the same as described in Table 4. 
that suppliers from Asia are emerging with products prices lower by an order of magnitude as compared to Western suppliers, especially in the low- and middle-size PEM market. However, alkaline electrolyser still remains the preferred technologies for larger scale hydrogen production. The main component of alkaline electrolysers is described and the layout of a typical alkaline electrolysis plant is presented. Additionally, the electrolysis process is modeled analytically. The model includes the dependence of the electrolyte conductivity on temperature. For typical parameters of an AEL electrolyser, it is found that the major loss contribution springs from the over-potential at the anode (57\%), followed by losses through conduction in the electrolyte (26\%) and over-potential at the cathode (17\%). The model developed can be used to determine the optimal design and operation point of a system.

\section{Acknowledgements}

The authors gratefully acknowledge the financial support of the Swiss National Science Foundation (NSF) within the project RMTM-Renewable Methane for Transport and Mobility.

\section{References}

[1] Stocker, T.F., et al. (2013) IPCC, 2013: Climate Change 2013: The Physical Science Basis. Contribution of Working Group I to the Fifth Assessment Report of the Intergovernmental Panel on Climate Change.

[2] Wirth, H. and Schneider, K. (2013) Recent Facts about Photovoltaics in Germany. Fraunhofer Institute for Solar Energy Systems ISE, Freiburg.

[3] Schlapbach, L. and Züttel, A. (2001) Hydrogen-Storage Materials for Mobile Applications. Nature, 414, 353-358. https://doi.org/10.1038/35104634

[4] Züttel, A., Mauron, P., Kato, S., Callini, E., Holzer, M. and Huang, J. (2015) Storage of Renewable Energy by Reduction of CO2 with Hydrogen. Chimia, 69, 264-268. https://doi.org/10.2533/chimia.2015.264

[5] US DoE (2004) Fuel Cell Handbook. EG \& G Technical Services, Morgantown.

[6] Bernadet, L., Gousseau, G., Chatroux, A., Laurencin, J., Mauvy, F. and Reytier, M. (2015) Influence of Pressure on Solid Oxide Electrolysis Cells Investigated by Experimental and Modeling Approach. International Journal of Hydrogen Energy, 40, 12918-12928. https://doi.org/10.1016/j.ijhydene.2015.07.099

[7] Siemens (2016) SILYZER-Hydrogen Solutions-Siemens. https://www.industry.siemens.com/topics/global/en/pem-electrolyzer/silyzer/pages/ $\underline{\text { silyzer.aspx }}$

[8] Ulleberg, O. (2016) Local Hydrogen Supply for Energy Applications. World Hydrogen Energy Conference ( WHEC), Zaragoza, 13-16 June 2016.

[9] Bertuccioli, L., Chan, A., Hart, D., Lehner, F., Madden, B. and Standen, E. (2014) Development of Water Electrolysis in the European Union. Fuel Cells Hydrogen Joint Undertakings, Lausanne.

[10] Smolinka, T. (2014) Water Electrolysis: Status and Potential for Development. Fraunhofer Institute for Solar Energy Systems ISE, Freiburg.

[11] LeRoy, R.L. (1983) Industrial Water Electrolysis: Present and Future. International Journal of Hydrogen Energy, 8, 401-417. 
[12] Ulleberg, O. (2003) Modeling of Advanced Alkaline Electrolyzers: A System Simulation Approach. International Journal of Hydrogen Energy, 28, 21-33.

[13] Rosa, V.M., Santos, M.B.F. and Da Silva, E.P. (1995) New Materials for Water Electrolysis Diaphragms. International Journal of Hydrogen Energy, 20, 697-700.

[14] Hickner, M.A., Ghassemi, H., Kim, Y.S., Einsla, B.R. and McGrath, J.E. (2004) Alternative Polymer Systems for Proton Exchange Membranes (PEMs). Chemical Reviews, 104, 4587-4612. https://doi.org/10.1021/cr020711a

[15] Oldham, K. and Myland, J. (2012) Fundamentals of Electrochemical Science. Elsevier.

[16] Janjua, M.B.I. and Le Roy, R.L. (1985) Electrocatalyst Performance in Industrial Water Electrolysers. International Journal of Hydrogen Energy, 10, 11-19.

[17] Dyer, C.K. (1985) Improved Nickel Anodes for Industrial Water Electrolyzers. Journal of the Electrochemical Society, 132, 64-67. https://doi.org/10.1149/1.2113793

[18] Kim, S., Koratkar, N., Karabacak, T. and Lu, T.-M. (2006) Water Electrolysis Activated by $\mathrm{Ru}$ Nanorod Array Electrodes. Applied Physics Letters, 88, Article ID: 263106. https://doi.org/10.1063/1.2218042

[19] Renaud, R. and Le Roy, R.L. (1982) Separator Materials for Use in Alkaline Water Electrolysers. International Journal of Hydrogen Energy, 7, 155-166.

[20] Vermeiren, P., Adriansens, W. and Leysen, R. (1996) Zirfon: A New Separator for $\mathrm{Ni} \mathrm{H} 2$ Batteries and Alkaline Fuel Cells. International Journal of Hydrogen Energy, 21, 679-684.

[21] Burnat, et al. (2015) Composite Membranes for Alkaline Electrolysis Based on Polysulfone and Mineral Fillers. Journal of Power Sources, 291, 163-172.

[22] Zeng, K. and Zhang, D. (2010) Recent Progress in Alkaline Water Electrolysis for Hydrogen Production and Applications. Progress in Energy and Combustion Science, 36, 307-326.

[23] Yushkevich, V.Y., Maksimova, I.N. and Bullan, V.G. (1967) Electrical Conductivity of Potassium Hydroxide Solutions at High Temperatures. Elektrokhimiya, 3, 1491-1493.

[24] Etsell, T.H. and Flengas, S.N. (1970) Electrical Properties of Solid Oxide Electrolytes. Chemical Reviews, 70, 339-376. https://doi.org/10.1021/cr60265a003

[25] Lee, C.H., Park, H.B., Lee, Y.M. and Lee, R.D. (2005) Importance of Proton Conductivity Measurement in Polymer Electrolyte Membrane for Fuel Cell Application. Industrial \& Engineering Chemistry Research, 44, 7617-7626. https://doi.org/10.1021/ie0501172 